This article was downloaded by: [University of Sheffield]

On: 16 June 2010

Access details: Access Details: [subscription number 919726257]

Publisher Routledge

Informa Ltd Registered in England and Wales Registered Number: 1072954 Registered office: Mortimer House, 3741 Mortimer Street, London W1T 3JH, UK

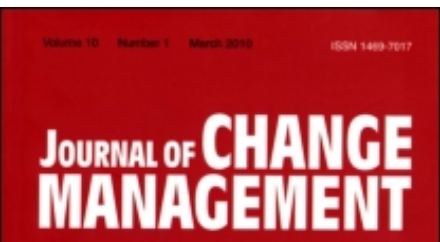

\title{
Journal of Change Management
}

Publication details, including instructions for authors and subscription information:

http://www.informaworld.com/smpp/title content=t713703618

\section{Strategic management and organization development: Planned change in a} public sector organization

Harry Sminia ${ }^{a}$; Antonie Van Nistelrooij ${ }^{\mathrm{b}}$

${ }^{\text {a }}$ The Management School, University of Sheffield, UK ${ }^{\mathrm{b}}$ Department of Administrative and

Organization Science, Faculty of Social Sciences, Vrije Universiteit, Amsterdam

To cite this Article Sminia, Harry and Van Nistelrooij, Antonie(2006) 'Strategic management and organization development: Planned change in a public sector organization', Journal of Change Management, 6: 1, 99 - 113

To link to this Article: DOI: $10.1080 / 14697010500523392$

URL: http://dx.doi.org/10.1080/14697010500523392

PLEASE SCROLL DOWN FOR ARTICLE

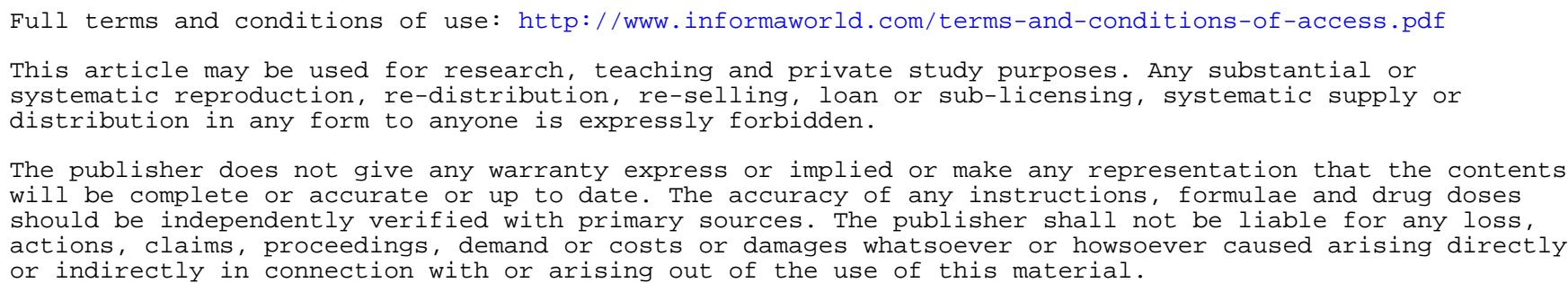




\title{
Strategic Management and Organization Development: Planned Change in a Public Sector Organization
}

\author{
HARRY SMINIA* \& ANTONIE VAN NISTELROOIJ** \\ ${ }^{*}$ The Management School, University of Sheffield, UK, ${ }^{* *}$ Department of Administrative and Organization \\ Science, Faculty of Social Sciences, Vrije Universiteit, Amsterdam
}

\begin{abstract}
This paper reports on a case study on the introduction of organization development $(O D)$ techniques in a traditionally top-down lead public sector organization in the Netherlands. The findings suggest that an OD-inspired bottom-up change approach can have a place next to a top-down strategic management change approach. However, to reap the benefits of OD, the top management role appeared to be pivotal, especially with regard to creating the circumstances under which sufficient participation can take place.
\end{abstract}

KeY WoRds: Organization development, strategic management, management of change, public sector, process research

\section{Introduction}

Organization development (OD) is used increasingly in strategic change initiatives in public sector organizations (Ferlie et al., 1996; Robertson and Seneviratne, 1995; Patchett, 2005; Teo and Crawford, 2005). The reasons for strategic change in the public sector are mostly found in abrupt and predominantly exogenous jolts such as changing policies or legislation, technological change, top management replacements or reorganizations such as the joining together or the breaking up of public agencies. These kinds of development require decisive and large scale strategic change to regain congruence between the organization's goals, the environment and the organization. In these instances, public sector organizations have a tendency to adopt a strategic-management-inspired approach of generating change in a top-down fashion (Ferlie et al., 1996). Such an approach

Correspondence Address: Harry Sminia, The Management School, University of Sheffield, 9 Mappin Street, Sheffield, S1 4DT, UK. Email: h.sminia@shef.ac.uk 
seems particularly appropriate because the top management team is in the best position to initiate and implement quick and purposeful organizational change, and they have the means and the position to work from a system-wide perspective that does not reflect functional or departmental biases (Conger, 2000; Jensen, 2000). From an OD point of view, however, a bottom-up approach with the full participation and active involvement of all employees is seen as essential for generating commitment and ensuring the strategic reorientation actually is realized (Beer, 2000; Bennis, 2000; Dunphy, 2000; French et al., 2000; Cummings and Worley, 2005). The combination of both approaches is not an easy matter as a number of case studies have shown (Bate et al., 2000; Beer, 2001; O'Brien, 2002; Balogun and Hailey, 2004; Burnes, 2004).

There are a number of profound differences between public sector organizations and private sector organizations when it comes to organizational change (Robertson and Seneviratne, 1995; Ferlie et al., 1996; Coram and Burnes, 2001; O'Brien, 2002; Härenstam et al., 2004). In many cases not only are the reasons different for initiating change but also change concepts and approaches that are transferred from the private sector to the public sector can lead to contradictory results. In comparison to private organizations, public organizations are more characterized by a multitude of decision-makers, by a larger diversity of stakeholders, by more intensive organizational dynamics and by a more bureaucratic organizational design. Or as Patchett (2005: 598-9) puts it: 'The political nature of the legislative and representation process and the functional expert and efficiency orientation of the administrative process produce important tensions in a public-sector organization.' The particular context of a public organization puts specific demands on the management of change, for instance, with regard to working with different authorities and handling the influence of legislation and the political field of force effectively.

This paper reports on a case study of strategic change at a public organization in the Netherlands. The focus is on the question of whether bottom-up OD methods can be adopted alongside the strategic-management-inspired approach of topdown lead change. As with so many public organizations, a tradition existed in this organization to initiate and manage change from the top. By incorporating OD methods in the project design, an attempt was made to avoid some of the disadvantages of the strategic management approach and to benefit from the strong points of the OD approach. The remainder of this paper is organized as follows. First the management of change in the public sector in general will be further explored. Second the particularities of the case will be described as well as the methods that were employed in this case study. The case will be analysed next, and the paper ends with discussion and conclusions.

\section{Management of Change in the Public Sector}

Ferlie et al. (1996: 86) described the management of change in the public sector as 'top-down radical shock strategies and the exercise of political clout'. This clearly fits the strategic management approach where strategic change is achieved by way of a pre-designed top-down implementation process after the content of the new strategy has been formulated (Dunphy, 2000; Balogun and Hailey, 2004; 
Burnes, 2004). However, comparisons between decision-making in public and in private organizations have revealed that successful implementation in the public sector also requires a bottom-up approach with some degree of employee participation (Rodrigues and Hickson, 1995; Hickson et al., 2003). This explains the growing interest in OD concepts and methods in the public sector (Robertson and Seneviratne, 1995; Ferlie et al., 1996; Patchett, 2005; Teo and Crawford, 2005). Nevertheless, the introduction of OD in organizations that are accustomed to centralized control and bureaucratic and political working conditions may clash with the prevailing organization culture or can even be perceived as undermining the public administration work ethos (Barnhart, 1997; O'Brien, 2002).

Both the OD approach as well as the strategic management approach are archetypes, based on plausible and legitimate premises (Beer and Nohria, 2000a). Because of their complementarities (Hickson et al., 2003; Cummings and Worley, 2005) they are considered to be insufficient for the successful implementation of strategic change when applied separately (Beer, 2001; Hickson et al., 2003). 'A purely top-down effort, in which there is little or no participation within the organization, is just as likely to end in failure as a purely bottom-up approach' (Conger, 2000: 101). Coram and Burnes (2001) and O'Brien (2002) have drawn similar conclusions based on their case studies. These observations imply that a combination of both approaches seems to be the most fruitful option.

There are several ways of dealing with different approaches to organizational change in one project. One way is to adopt a contingency perspective where the circumstances are outlined under which a particular approach is considered to be more appropriate to be able to time and sequence the approach to the course and the requirements of the change process (Huy, 2001; Boonstra, 2004; Waldersee and Griffiths, 2004). Beer and Nohria (2000b) and Beer (2001) warn against such a solution of alternating different approaches through time. They argue this leads to confusion and delay and the process will suffer more from the disadvantages of both approaches than that it will benefit from the advantages. They do see a possibility of starting with the top-down strategic management approach to achieve a quick and definitive turnaround, followed through by an OD bottom-up change programme to anchor a new way of doing things in the organization. This does require a very carefully lead change programme by which confidence, commitment and trust destroyed during the first phase needs to be carefully rebuilt during the second phase. Nevertheless, they consider this to be the exception to the rule. The other way around, they argue, spells disaster. Anything that has been built up during an initial OD initiative will be destroyed if it is followed up by a top-down strategic management style turnaround - leaving the organization behind with a high level of distrust and no commitment, confidence or shared purpose. Beer and Nohria (2000b) and Beer (2000) emphasize the complementary character of strategic management and OD instead to propose a simultaneous approach where both approaches are integrated into one. They admit applying their simultaneous approach in practice is difficult to do, but they provide a number of pointers by which they say the contradiction can be managed. Reading through their material, the following guidelines can be extracted: 
1. The tension between top-down and bottom-up goals needs to be confronted explicitly;

2. Direction needs to be set from the top and people need to be engaged from below;

3. Management needs to embody the assumptions and styles of both approaches;

4. The focus needs to be on both organization design and organization culture;

5. The change process needs to be partly planned in advance but also to allow for emergent experimentation and problem solving.

These pointers are illustrated with examples from a change process that occurred at the British grocery chain of Asda. These recommendations, however, are perhaps more an elaboration of the contradiction that is inherent in combining the top-down strategic management approach with the bottomup OD approach to change than actually providing workable solutions to manage the tensions.

Therefore there remains the question how such a simultaneous approach works out in practice. This is an especially compelling question for public sector organizations because of their interest in introducing bottom-up change programmes and their history of top-down change efforts. What effects exactly are to be expected when OD is introduced alongside strategic management in the public sector? A number of cautions need to be observed when OD is introduced in a predominantly strategic-management-like context. Firstly, the issues that are going to be subject to OD need to be selected carefully and have to have real significance. Or as Kanter (1983:254) pointed out: 'People are skeptical about participation just for show, without any impact on substance.' Secondly, top management has to create the possibility for people to participate and contribute to the development and implementation of the strategic change. The expectation is that if these two recommendations are not observed, the OD part of a process of strategic change will not have the effects it was intended to have.

\section{The ViZieR project at UWV}

The UWV organization in the Netherlands provided a research opportunity to study a process of planned change in the public sector. UWV is the administrative organization for the Dutch collective employee benefit regulations. This organization came into existence on 1 January 2002 by merging the previously existing seven separate administrative organizations into one. As a consequence of the merger, the VizIeR project was started in March 2002 (VizIeR stands for Voorzieningen Inkoop Reïntegratie, or provisions purchasing reintegration). This project concerned the work area of disablement and more specifically the purchase of services from external suppliers that aim to help long-term ill and (partly) disabled workers to reintegrate into a work situation, and the provision of these services to workers, employers and others that need them. The aim of the VizIeR project was to have a new organizational unit within UWV up and running by September 2003, capable of handling 90 per cent of the applications within six weeks according to a generic and transparent newly designed work 
process, accompanied by a new administrative system. This project potentially affected about 550 people within UWV.

The UWV organization and the earlier seven administrative organizations have upheld a tradition of pre-designed top-down-led change programmes. This time UWV management was willing to introduce OD practices to foster employee participation because it realized the ViZieR project not only involved changes with regard to the strategy and structure but also the development of new working practices and patterns of cooperation between people from the former seven administrative organizations and between two UWV departments. Each one of the original seven administrative organizations had worked according to their own procedures, often with outdated administrative systems. What needed to be done was a complete redesign of the work processes and administrative system of the UWV department IR. The IR department had been newly created for this part of the collective employee benefit regulations - IR stands for Inkoop (purchasing) and Reïntegratie (reintegration). They also had to develop a working relationship with the AG department, which assessed the (dis)ability levels of the people who were on benefit: AG stands for Arbeidsgeschiktheid (work ability).

The UWV management's willingness to work with OD methods led to a simultaneous change approach for this project that distinguished between a 'change strand' and a 'project strand'. The 'project strand' had to work on the organization design, the procedures, the work standards and the supporting ICT system. It was structured as an engineering project with set deadlines and specific design targets while people worked in a strict hierarchy. The 'change strand' was supposed to

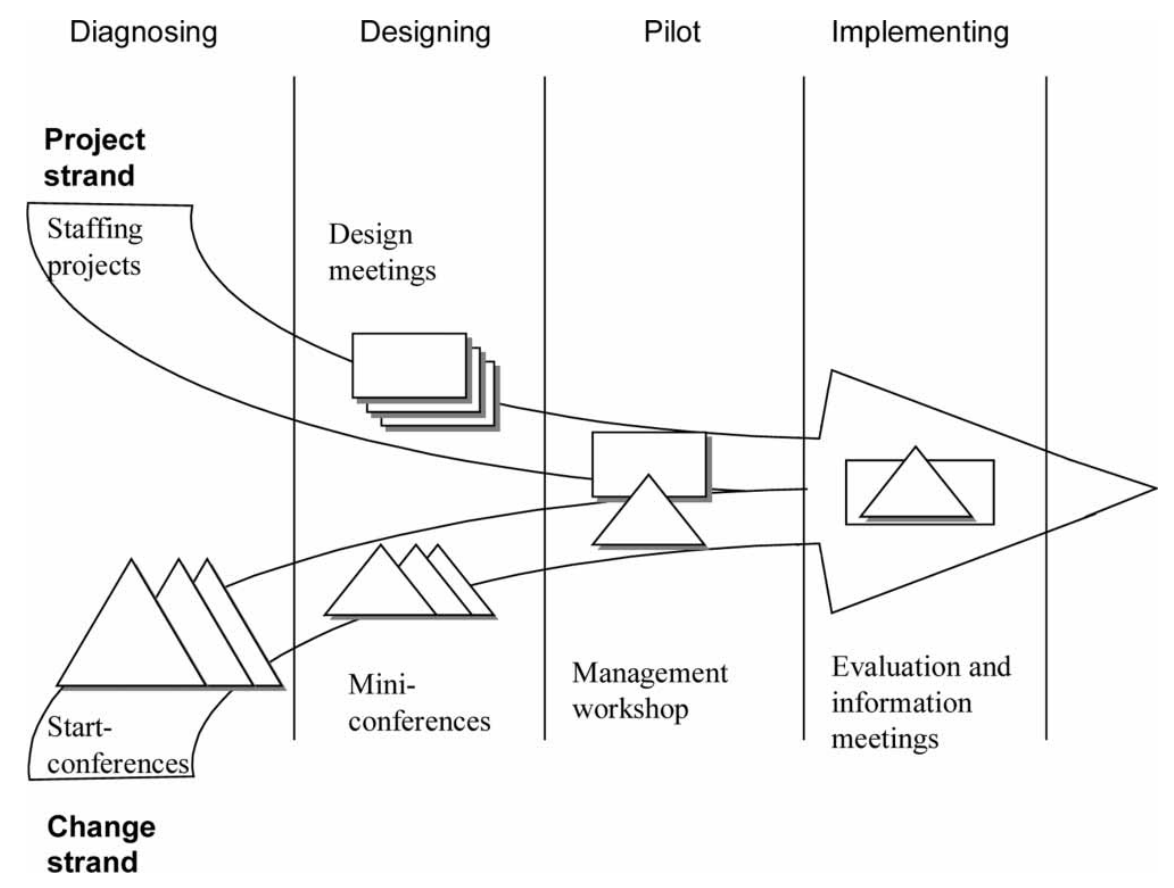

Figure 1. Project design 
feed the 'project strand' with the information needed to develop the new work processes and administrative system. It also had to help to lay the foundation for a new frame of reference for the newly created UWV organization as a whole, to ease implementation and to improve cooperation between departments. The 'change strand' featured a programme of OD-type interventions, based on large scale intervention (LSI) techniques (Van Nistelrooij et al., 2004). This strand had to start off with starting conferences and mini-conferences that had to develop the first design parameters and to decide on the staffing of a variety of sub-projects. This was to be followed up by workshops, informative meetings and evaluative meetings to support the pilot and implementation of the new design. These two strands would be on separate but simultaneous tracks initially, but were supposed to merge during the course of the change project.

\section{Method}

The methods that have been used to investigate this case were aimed at tracking and analysing the course of the ViZieR project through time. A process approach has been adopted to be able to describe and explain the course and the outcome by way of the events that make up the process (Mohr, 1982; Langley, 1999; Poole et al., 2000). Consequently, process is defined as a sequence of events (Miles and Huberman, 1994; Van de Ven and Poole, 1995; Poole et al., 2000) which makes the event the basic process parts (Abott, 1990; Peterson, 1998). This means, firstly, that for the purpose of this research, the events making up the ViZieR project need to be gathered longitudinally. Secondly, by coding these events in a theoretical meaningful way, a historical baseline can be composed by listing these events in the chronological order in which they occurred. In this manner the course of the change project can be assessed and analysed and the outcome explained.

The ViZieR project introduced new OD change methods into the UWV organization alongside existing strategic-management-like practices. It was assumed that if these new methods were to be adopted successfully, they had to become institutionalized in their own right as common practices among the existing organizational routines. Looking at it this way, the VizieR project not only aimed to reorganize a part of the UWV organization, it also had to alter the manner in which change was routinely introduced and effected. Barley and Tolbert (1989) propose to study institutional change by charting flows of actions to see if and how what they call 'scripts' have become subject to change over time. They define scripts as 'observable, recurrent activities and patterns of interaction characteristics of a particular setting' (Barley and Tolbert, 1989: 98). Furthermore, to them scripts are taken to stand for particular institutionalized interaction patterns which in turn are subject to a process of structuration (Giddens, 1976). Structuration theory sees human action as shaping and as being shaped by these scripts. On the one hand, these scripts prescribe what the appropriate action is in a particular situation. On the other hand, human action gives rise to the emergence and the preservation of scripts when these actions change or conform to certain regularities. 
We decided to single out three specific scripts where the tensions between topdown and bottom-up change would be very prominent. These are: (1) the power of decision script; (2) the project focus script; and (3) the participants' role script. According to the strategic management logic, the power of decision lies with the top management team. However, in line with the OD logic, the participants are supposed to be empowered to make their own decisions. With regard to the project focus script, the question is whether the focus of the project activities is on hierarchy and on satisfying the needs of (top) management (strategic management logic), or whether the focus is on the participants and making sure that everybody participates (OD logic). The participants' role script in strategic management mode expects participants to be more passive with regard to their involvement in the project, while the OD logic requires a more active stance from every participant. This means that the event data that are going to be analysed have to reveal how these three scripts are going to develop over time. In other words, is there going to be room for the OD logic next to the strategic management or SM logic with regard to these change scripts over the course of the ViZieR project?

We have collected the raw data by recording events over the duration of the VizIeR project. These events were either gathered by direct observation during various meetings and gatherings or were derived from documents that were produced as a consequence of the change project. Observation took place on 49 occasions, while 41 documents were used as a data source. The time period over which events were recorded lasted from 1 January 2002 until 17 December 2003. This resulted in a database filled with a total of 640 recorded events. Each event record contained information about the date when it occurred, the actor and the act that made it up, and the source. The events were subsequently coded in terms of the three scripts as well as the change logic that was reflected in each event.

In accordance with the recommendation of Barley and Tolbert (1997) to validate the observations and conclusions with additional data, a questionnaire was distributed among a sample of 152 participants in the ViZieR project in June 2003. The questionnaire was aimed specifically at measuring the perceptions and experiences of the people who participated in the project. Questions were asked about the modes of communication, the degree to which communicated information had been received and understood and to what the degree the participants thought the goals of the project had been achieved.

\section{Analysis of the ViZieR project}

In keeping with the project design, the diagnostic phase started with three largescale conferences. These were identical conferences conducted within a short space of time but spread out over the country to give every participant the opportunity to attend. These first meetings explained and legitimized the OD part of the change process and were mostly concerned with the project focus script. On many occasions the message to the participants was that their efforts and input were going to be considered as essential for the success of the project and that they had to take advantage of the situation by being able to make their mark on the UWV organization. For instance, the project manager during his presentations 
Table 1. Change logic and script coding scheme

SM logic OD logic

Power of decision script

Management team (MT) emphasis when:

- MT sets framework

- MT sets roles and positions

- MT decides on what is essential

- MT determines mode of communication

- MT sets purpose

- MT determines course of events

- MT manages through results

- MT assesses products

- MT ignores 'change-strand'
Participants $(\mathrm{P})$ emphasis when:

- P decide on content and process issues

- P set roles

- P set purpose and results

- P answer questions on content and process issues

- emphasis is on involvement workers

- emphasis is on discussion and decision by workers

- 'change-strand' is encouraged
Project is focused on MT when:

- there is anticipation on expectations of MT

- there is a need of convincing MT

- there is a wish for clarity from MT

- there is doubt about MT support

- there is fear that framework already has been decided upon

- there is significance attached to MT statements

Passive role of participants when:

- P await MT decisions

- P await change

- P await communications

- P refrain from judgement

- documents are not distributed on time

- work process has been set beforehand
Project focus script

Project is focused on participants when:

- there is a need to communicate with whole organization

- there is a need for full participation

- there is a need to preserve "processstrand' consultants

- there is a need to involve whole organization

- there is creation of full ownership of new organization design

- new organization design is tested among workers

Participants' role script

Active role of participants when:

- P make suggestions for project process and content

- P make suggestions for new organization design

- P make judgement

- P show initiative

- P make project larger

- P show commitment

in the start-up conferences emphasized the significance of this new way of achieving change by stating: 'Let's seize the opportunity... because we have been granted the space to create a good working process. If you can blow a hole; please do, and make the work process better.' He added that 'management has decided willingly in favour of a bottom-up approach; everyone can take part, everyone can have influence and every voice is important' (translated from Dutch).

With regard to the power of decision script, however, the message was more mixed. On the one hand, UWV management indicated they were anxious to reap the benefits from the bottom-up approach that was designed into the 
project. They also insisted a number of restrictions had to be taken into account and certain requirements that management had decided upon needed to be met. The representative of UWV management in the start-up conferences told the participants that 'actually everything is under discussion' and that 'there are few restrictions', but also that 'I want to instate regional managers' and 'I want you to meet a number of conditions' already shaping the design and setting the boundaries before the design process actually had started.

In the course of the diagnostic phase, a rift between the IR and AG departments within UWV developed concerning the specific content and demarcation of the future tasks of the IR department. Employees working in the AG department, who would have to cooperate closely with the IR department for which new work processes were being designed, feared that too much of their work would be transferred to the IR department. A casual remark of the acting project manager about the possibility that 90 per cent of the workload was going to be allocated to the IR department had distressed the AG employees. The project manager had only made this remark to provide an example, with the intention simply of challenging the participants to think the unthinkable. Some time later, the 90 per cent/10 per cent division of tasks was believed to have the status of a management decision, which it had not, but the AG people were up in arms because they feared for their position within UWV. This rift stalled the progress of the project as a whole and top management decided to intervene. Furthermore, just before the top management intervention took place, the members of the project team learned to their amazement that the project manager was ignorant of the meaning of LSI, that he had no idea what it entailed nor that the 'change strand' of the ViZieR project had been designed according to LSI principles.

Because UWV top management thought the project was loosing momentum as a consequence of the rift between the IR and AG departments, they appointed a special consultant to the ViZieR project. He convened a 'kick-off meeting' on 13 January 2003 to put the project back on track and introduced a project methodology that was aimed at achieving substantial results. This meeting also was taken to mark the transition from the diagnostic phase to the design phase of the project. As a consequence the emphasis was put on the 'project strand' and the design of the new work processes. The sub-projects were staffed and went to work on their specific tasks. The first results were presented to the larger project community during a number of mini-conferences that originally had been scheduled as part of the 'change strand'. The character of these mini-conferences, however, had changed considerably when compared to the original plan. The emphasis was on substance and not on process and dialogue. The participants were just asked to comment on the designs that had been drafted in the sub-projects. On a number of occasions, the discussions referred to the rift between the IR and AG departments, but an attempt to actually deal with this problem was not really made. The overall conclusion after the last mini-conference had been held was that these first designs were incomplete and progress had been disappointing. By then it was the end of February 2003.

During this part of the design phase, events signalled all kind of messages concerning each of the three scripts. With regard to the power of decision script, 


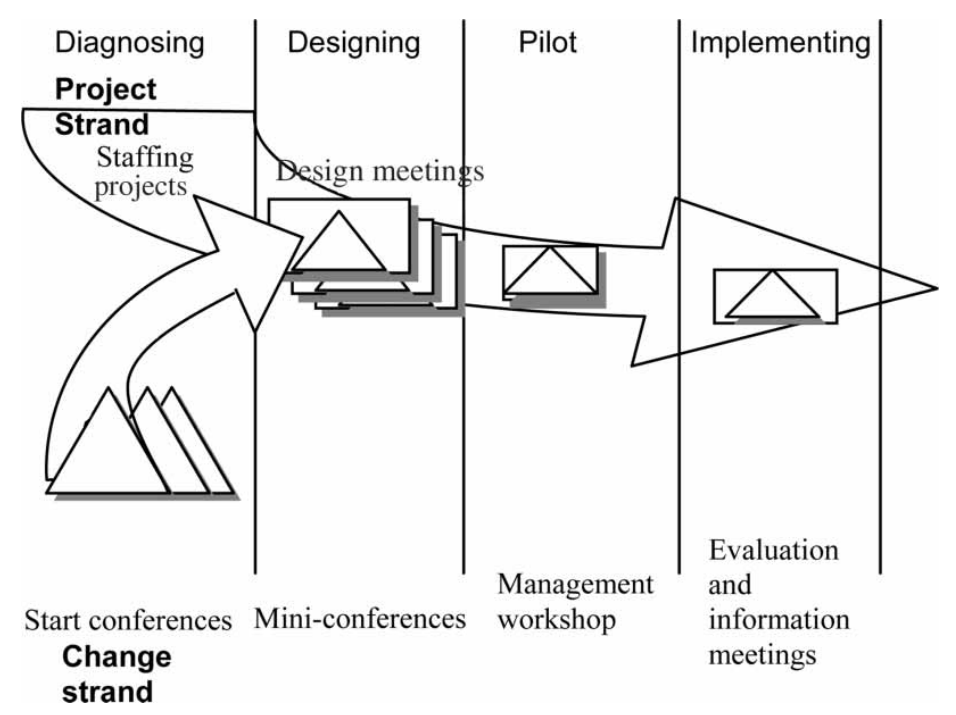

Figure 2. Realized project

specifically in meetings immediately following the kick-off meeting on 13 January, UWV management further emphasized what they saw as being a good project result and that they wanted results quickly, more or less signalling that they had the final say when choices are being made. The messages with regard to the project focus script were mixed. On the one hand, the special consultant introduced a methodology that focused on the participants and the opportunity to voice their concerns and ideas about the work process design and he continuously made remarks about how they all were part of the project. On the other hand, the rift between the AG and IR departments started to become a taboo subject because management perceived this to be the main cause of the lack of progress, while this was a major concern for many of the participants. Informal comments started to become more and more laden with disappointment and reproach such that the 'change strand' purpose of dialogue by way of LSI had disappeared from the project course. The participants' role script was particularly present during the mini-conferences. The participants seized the opportunity to actively comment on the designs, as they had been asked to do. Nevertheless, bad preparation, failures to brief the participants in advance of what was to be expected of them and failures in getting conference documents to the participants in time forced them into passivity as well. Management also appeared to be not too eager to receive critical remarks from the employees, judging from informal remarks referring to the possibility of 'boarding everything up before the mini-conferences start so that it cannot be discussed any more'.

As a consequence of the continuing lack of progress, the targets for the 'project strand' were changed to the extend that the blueprint for the UWV department IR, including the new work process and the administrative system, had to be ready to be implemented in pilots at two separate locations as soon as possible. Also the design phase of the ViZieR project changed character completely. UWV top 
management in a meeting on 6 March 2003 instructed IR and AG departmental management directly what it was that they wanted and how they wanted it to be achieved, to resolve the differences between the two departments. Again the message with regard to the power of decision script was that it is management who make the decisions. From this moment onwards there are hardly any events observed that make reference to the project focus script or the participants' role script in either one way or the other.

During the course of April 2003, the design phase was gradually changing over into the pilot phase as a first complete work process design was being finalized and preparations were being made to test the new procedures at two selected sites. During these tests, the local employees and managers who were trying things out continuously, needed to change and amend the design to work out how it might become operational. By allowing this to happen, the power of decision script as well as the project focus script and the participants' role script appeared to be leaning towards the bottom-up approach. However, in a project management meeting on 17 June 2003, the project manager informed the participants that UWV management had decided to declare an end to the ViZieR project and that the new work processes were going to be implemented in a top-down fashion, utilizing the standing management and organization structure. The implementation phase effectively was lifted out of the project.

Combining the overall findings with regard to the three scripts, it appeared that the ViZieR project started off in a manner in which the bottom-up OD approach seemed to have had equal significance alongside the top-down strategic management approach, although the power of decision remained firmly in the hands of UWV top management. The top management intervention at the end of the diagnostic phase, emphasizing the SM-inspired 'project strand' over the OD-inspired 'change strand', shifted the balance between the two perspectives. During the subsequent design phase, initially there were claims being made in favour of the OD perspective, but with the second top management intervention in the project, these claims disappeared from the process and the strategic management perspective gained the upper hand.

The results from the questionnaire confirm these observations. The targets from the original 'project strand' by and large had been reached, but not on the original deadline. After the ViZieR project was officially ended with the finish of the two pilots, the new design was cascaded out over the whole UWV organization. In less than 18 months since the implementation of the new operating procedures started, all UWV offices were able to deal with 90 per cent of applications within six weeks. The new ICT system also was fully operational. Looking at the targets from the original 'change strand', however, the results lagged behind. Only 27.7 per cent of the participants confirmed an increased readiness for change and only 29.9 per cent indicated the new operating procedures had sufficient support among UWV employees. While 76.9 per cent indicated their commitment to UWV had not increased as a consequence of the ViZieR project, 52.2 per cent did state that communication between the original seven organizations that merged into UWV had improved, although only 27.7 per cent indicated the same for the communication between the AG and IR departments. Other aspects that the respondents felt were still worth improving were project 
management skills, raising employees' commitment to the project and the readiness of top management to listen to the shop floor.

\section{Discussion and Conclusion}

Can OD be introduced alongside the strategic management approach to change in the public sector? The UWV case revealed that this is a possibility, but the role of top management has proven to be essential in this. The start-up of the ViZieR project showed that the OD logic had become part of the process, at least with regard to the project focus script and the participants' role script during the first two phases. With regard to the power of decision script, however, the UWV practice of this being a top management prerogative was being challenged throughout the project; but the top team apparently felt obliged to hold on to the privilege. This was, of course, amply demonstrated by their intervention, which changed the initial project design by putting the 'project strand' first and the 'change strand' second. This did not kill off the initial enthusiasm of the UWV workforce right away, judging from the presence of the OD logic in events during the subsequent design phase. However, OD references with regard to the project focus script and the participants' role scripts more or less disappeared from the scene during the remainder of the project, indicating that the strategic management logic had prevailed.

The UWV case demonstrates that the simultaneous approach to strategic change is not an easy matter. There are two observations that can be made as a consequence of the UWV experience. Firstly, there is the specific role of OD in a simultaneous approach to strategic change. The plan was to utilize the results from the 'change strand' as inputs in the 'project strand' of the ViZieR project. Initially this set-up worked reasonably well. Not only did this result in the specifications for an initial design of the new work process, it also helped to staff the subsequent subprojects. However, it emerged that UWV top management gave preference to the 'project strand' and the realization of the associated goals. Although the project was designed according to the simultaneous approach to strategic change, it appeared that the top team was working according to a contingent approach, trying to time and sequence the approach to what they perceived as the course and the requirements of the change process. Judging from the responses of UWV employees, the effects mentioned by Beer (2000), Beer and Noria (2000b) and Kanter (1983) of introducing OD into an organization but not seeing it through during the whole project affected the course and outcome. Commitment, trust and confidence that were built up initially oozed away after UWV management had intervened and started working in a top-down fashion, introducing scepticism with regard to bottom-up change altogether.

Secondly, the top management role in creating the possibility for the employees to participate appeared to be essential for the course and the outcome of the change project. The three large-scale conferences at the beginning of the project have been an important step with regard to the level of cooperation between the various stakeholders. The results from the survey suggest that these conferences contributed to increased enthusiasm for and commitment to the project. However, the top management intervention and the subsequent change to the project design meant that these starting conferences appeared to be the only 
occasions when UWV employees were able to fully participate in the project. The promises of full participation made during the starting conferences were never completely fulfilled. Some respondents in the survey indicated they afterwards felt that they had been sent off empty handed.

All in all, the pivotal role of top management in the introduction of OD change practices came to stand out during the analysis of this strategic change project in the public sector. The workforce appeared to embrace the OD methods willingly, but they were not allowed to go the whole way when top management decided to intervene when the rift between the AG and IR departments emerged. The final success of the project with regard to the goals of the 'project strand' can be attributed to this intervention. However, by downplaying the 'change strand', the aims associated with this track within the project became largely unreachable as well; but this is not the only effect. UWV management refusal to share power with the employees and their intervention at a critical stage in the project severely hampered the dissemination of the OD logic alongside the strategic management logic. Instead, the UWV organization came out as a typical public organization, where change practices are dominated by top management and employee participation, initiative and commitment remain underdeveloped.

\section{Acknowledgements}

An earlier version of this paper was presented at the 20th EGOS Colloquim, Ljubljana, Slovenia, 1-3 July 2004. We would like to thank Floor Hesselmans for her assistance in gathering and analysing the data, and Hans Doodeman of UWV for facilitating and supporting this research project.

\section{References}

Abbott, A. (1990) A primer on sequence methods, Organization Science, 1, pp. 375-92.

Balogun, J. and Hailey, V.H. (2004) Exploring Strategic Change, 2nd edn (Harlow: Prentice-Hall).

Barley, S.R. and Tolbert, P.S. (1997) Institutionalization and structuration: Studying the links between action and institution, Organization Studies, 18, pp. 93-117.

Barnhart, T. (1997), Save the bureaucrats (while reinventing them), Public Personnel Management, 26, pp. 7-14.

Bate, P., Kahn, R. and Pyle, A.J. (2000) Culturally sensitive structuring: an action-research based approach to organization development and design, Public Administration Quarterly, 23, pp. 445-70.

Beer, M. (2000) Research that will break the code of change: The role of useful normal science and usable action science, in: Beer, M. and Nohria, N. (eds), Breaking the code of change (Boston, MA: Harvard Business School Press), pp. 429-447.

Beer, M. (2001) How to develop an organization capable of sustained high performance: Embrace the drive for results-capability development paradox, Organizational Dynamics, 29, pp. 597-619.

Beer, M. and Nohria, N. (eds.) (2000a) Breaking the code of change (Boston, MA: Harvard Business School Press).

Beer, M. and Nohria, N. (2000b) Cracking the code of change, Harvard Business Review, 78, pp. 133-141.

Bennis, W. (2000) Leadership of change, in: Beer, M. and Nohria, N. (eds.), Breaking the Code of Change (Boston, MA: Harvard Business School Press), pp. 113-22.

Boonstra, J. (2004) Conclusion: Some reflections and perspectives on organizing, changing, and learning, in: Boonstra, J. (ed.), Dynamics of Organizational Change and Learning (Chichester: John Wiley \& Sons), pp. 447-76.

Burnes, B. (2004) Managing Change: A Strategic Approach to Organizational Dynamics, 4th edn (Harlow: Pearson).

Conger, J.A. (2000) Effective change begins at the top, in: Beer, M. and Nohria, N. (eds), Breaking the Code of Change (Boston, MA: Harvard Business School Press), pp. 99-112. 


\section{H. Sminia \& A. van Nistelrooij}

Coram, R. and Burnes, B. (2001) Managing organizational change in the public sector - lessons from the privatization of the Property Service Agency, International Journal of Public Sector Management, 14, pp. 94-110.

Cummings, T.G. and Worley, C.G. (2005) Organization Development and Change, 8th edn (Cincinnati, OH: South-Western College Publishing).

Dunphy, D.C. (2000) Embracing the paradox: Top-down versus participative management of organizational change: a commentary on Conger and Bennis, in: Beer, M. and Nohria, N. (eds), Breaking The Code of Change (Boston, MA: Harvard Business School Press), pp.123-36.

Ferlie, E., Ashburner, L., Fitzgerald, L. and Pettigrew, A.M. (1996) The New Public Management In Action (Oxford: Oxford University Press).

French, W.L., Bell, C.H. and Zawacki, R.A. (2000) Organization Development and Transformation: Managing Effective Change, 5th edn (New York: McGraw-Hill).

Giddens, A. (1976) New Rules of Sociological Method (New York: Basic Books).

Härenstam, A., Bejerot, E., Leijon, O., Schéele, P., Waldenström, K. and MOA Research Group (2004) Multilevel analysis of organizational change and working conditions in public and private sector, European Journal of Work and Organizational Psychology, 13, pp. 305-43.

Hickson, D.J., Miller, S.J. and Wilson, D.C. (2003) Planned or prioritized? Two options in managing the implementation of strategic decision, Journal of Management Studies, 40, pp. 1803-36.

Huy, Q.N. (2001) Time, temporal capability and planned change, Academy of Management Review, 26, pp. 601-23.

Jensen, M.C. (2000) Value maximization and the corporate objective function, in: Beer, M. and Nohria, N. (eds), Breaking The Code of Change (Boston, MA: Harvard Business School Press), pp. 37-58.

Kanter, M. (1983) The Change Masters (London: Allen and Unwin).

Langley, A. (1999) Strategies for theorizing from process data, Academy of Management Review, 24, pp. 691-710.

Miles, M.B. and Huberman, A.M. (1994) Qualitative Data Analysis, 2nd edn (Thousand Oaks, CA: Sage).

Mohr, L.B. (1982) Explaining Organizational Behavior: The Limits and Possibilities of Theory and Research. (San Francisco, CA: Jossey-Bass).

O'Brien, G. (2002) Participation as the key to successful change - a public sector case study, Leadership \& Organizational Development Journal, 23, pp. 442-55.

Patchett, R.R. (2005) Organization development in the public sector, in: Cummings, T.G. and Worley, C.G. (eds), Organization Development and Change, 8th edn (Cincinnati, OH: South-Western College Publishing), pp. 596-603.

Perry, K.W. and Proctor-Thomson, S.B. (2003) Leadership, culture and performance: The case of the New Zealand public sector, Journal of Change Management, 3, pp. 376-99.

Peterson, M.F. (1998) Embedded organizational events: the units of process in organization science, Organization Science, 9, pp. 16-33.

Poole, M.S., Van de Ven, A.H., Dooley, K. and Holmes, M.E. (2000) Organizational Change and Innovation Processes. Theory and Methods for Research (New York: Oxford University Press).

Robertson, P.J. and Seneviratne, S.J. (1995) Outcomes of planned organizational change in the public sector: A meta-analytic comparison to the private sector, Public Administration Review, 55, pp. 547-58.

Rodrigues, S.B. and Hickson, D.J. (1995) Different organizations, differing reasons for success, Journal of Management Studies, 32, pp. 655-79.

Teo, S.T., and Crawford, J. (2005) Indicators of strategic HRM effectiveness: A case study of an Australian public sector agency during commercialization, Public Personnel Management, 34, pp. 1-16.

Van de Ven, A.H. and Poole, M.S. (1995) Explaining development and change in organizations, Academy of Management Review, 20, pp. 510-40.

Van Nistelrooij, A.T.M., De Vries, C. and Minkema, D. (2004) Dialoog en Whole Scale Change. Samengaan van open gespreksvoering en planmatige verandering, Opleiding \& Ontwikkeling; Tijdschrift voor Human Resource Development, 17, pp. 21-4.

Waldersee, R. and Griffiths, A. (2004) Implementing change: Matching implementation methods and change type, Leadership \& Organization Development Journal, 25, pp. 424-34.

\section{Notes on Contributors}

Dr Harry Sminia is Lecturer in Strategic Management at the Sheffield University Management School. His main research interest is in processes of strategy 
formation. He has been published in, among others, the Journal of Management Studies and the Scandinavian Journal of Management.

Dr Antonie van Nistelrooij is Assistant Professor of Organization Development and Change at the Vrije Universiteit Amsterdam. His special focus is on the effects of participation and dialogue during processes of intentional change. He researches in the fields of organizational behaviour, change management and OD. He has written books and articles with in these fields, in particular on the role of communication during large scale change projects. 